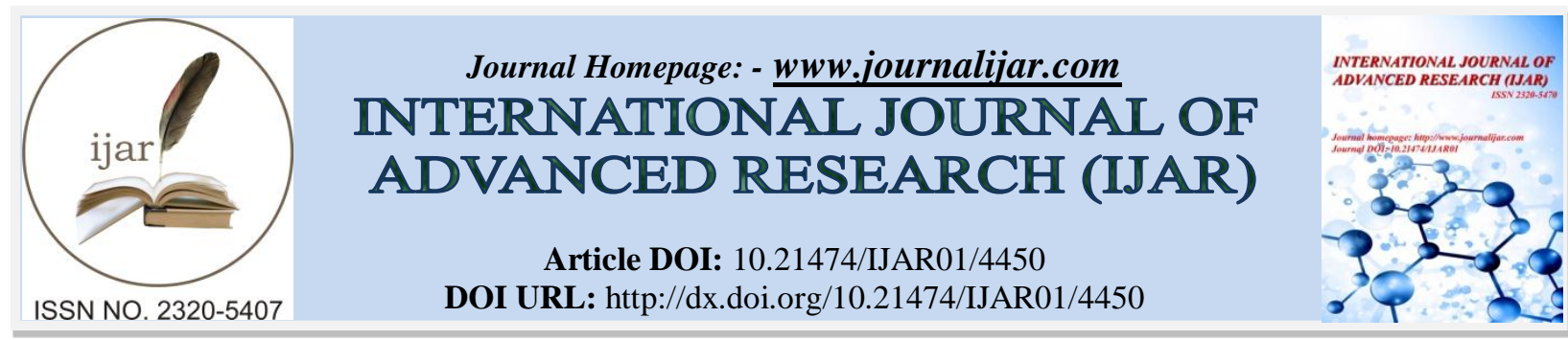

RESEARCH ARTICLE

\title{
TOWARDS ALTERNATIVE IBFS USING GUI TO OBTAIN SOLUTION TO TRANSPORTATION PROBLEM.
}

\begin{abstract}
Ms. Sarah Biju ${ }^{1}$, Mr. Rahul Bhatt ${ }^{1}$, Mr. Rony Mathew ${ }^{1}$ and Dr. N. Guruprasad ${ }^{2}$.
1. $8^{\mathrm{TH}}$ semester, Department of Computer Science \& Engineering, New Horizon College of Engineering, Bengaluru, India.

2. Professor - Department of Computer Science \& Engineering, New Horizon College of Engineering, Bengaluru, India.
\end{abstract}

\section{Manuscript Info}

Manuscript History

Received: 11 April 2017

Final Accepted: 13 May 2017

Published: June 2017

Key words:-

Feasible solution, Least Cost North

West, Optimal Solution, Vogel's

Approximation methods.

\section{Abstract}

The problem of finding the initial basic feasible solution of the Transportation Problem has long been studied and is well known to the research scholars of the field. So far three general methods for solving transportation methods are available in literature, namely Northwest, Least Cost and Vogel's Approximation methods. These methods give only initial feasible solution. However here we discuss a new alternative method which gives Initial feasible solution as well as optimal or nearly optimal solution. In this paper we provide an alternate method to find IBFS (Initial Basic Feasible Solution) and compared the alternate method and the existing IBFS methods using a Graphical User Interface. It is also to be noticed that this method requires lesser number of iterations to reach optimality as compared to other known methods for solving the transportation problem and the solution obtained is as good as obtained by Vogel's Approximation Method (VAM).

Copy Right, IJAR, 2017,. All rights reserved.

\section{Introduction:-}

The transportation problem itself was first formulated by Hitchcock (1941), and was independently treated by Koopmans and Kantorovich. In fact, Monge (1781) formulated it and solved it by geometrical means. Hitchaxic (1941) developed the basic transportation problem; however, it could be solved for optimally as answers to complex business problem only in 1951, when George B. Dantizig applied the concept of Linear programming in solving the transportation model. Dantzing (1951) gave the standard LP-formulation TP and applied the simplex method to solve it. Since then the transportation problem has become the classical common subject in almost every textbook on operation research and mathematical programming.

A typical transportation problem is shown in Table 1. It deals with sources where a supply of some commodity is available and destinations where the commodity is demanded. The classic statement of the transportation problem uses a matrix with the rows representing sources and columns representing destinations. The algorithms for solving the problem are based on this matrix representation. The costs of shipping from sources to destinations are indicated by the entries in the matrix. If shipment is impossible between a given source and destination, a large cost of $\mathrm{M}$ is entered. This discourages the solution from using such cells. Supplies and demands are shown along the margins of the matrix. As in the example, the classic transportation problem has total supply equal to total demand. 
Table 1:- Simple Transportation Tableau

\begin{tabular}{|c|c|c|c|c|}
\hline & D1 & D2 & D3 & Supply \\
\hline S1 & 3 & 1 & M & 5 \\
\hline S2 & 4 & 2 & 4 & 7 \\
\hline S3 & M & 3 & 3 & 3 \\
\hline Demand & 7 & 3 & 5 & \\
\hline
\end{tabular}

\section{Transportation Tableau:-}

The transportation problem can be described using linear programming mathematical model and usually it appears in a transportation tableau. The model of a transportation problem can be represented in a concise tabular form with all the relevant parameters. The transportation tableau (A typical TP is represented in standard matrix form), where supply availability (ai) at each source is shown in the far-right column and the destination requirements (bi) are shown in the bottom row. Each cell represents one route. The unit shipping cost (Cij) is shown in the upper right corner of the cell, the amount of shipped material is shown in the center of the cell. The transportation tableau implicitly expresses the supply and demand constraints and the shipping cost between each demand and supply point.

Table 2:- A detailed Transportation Tableau

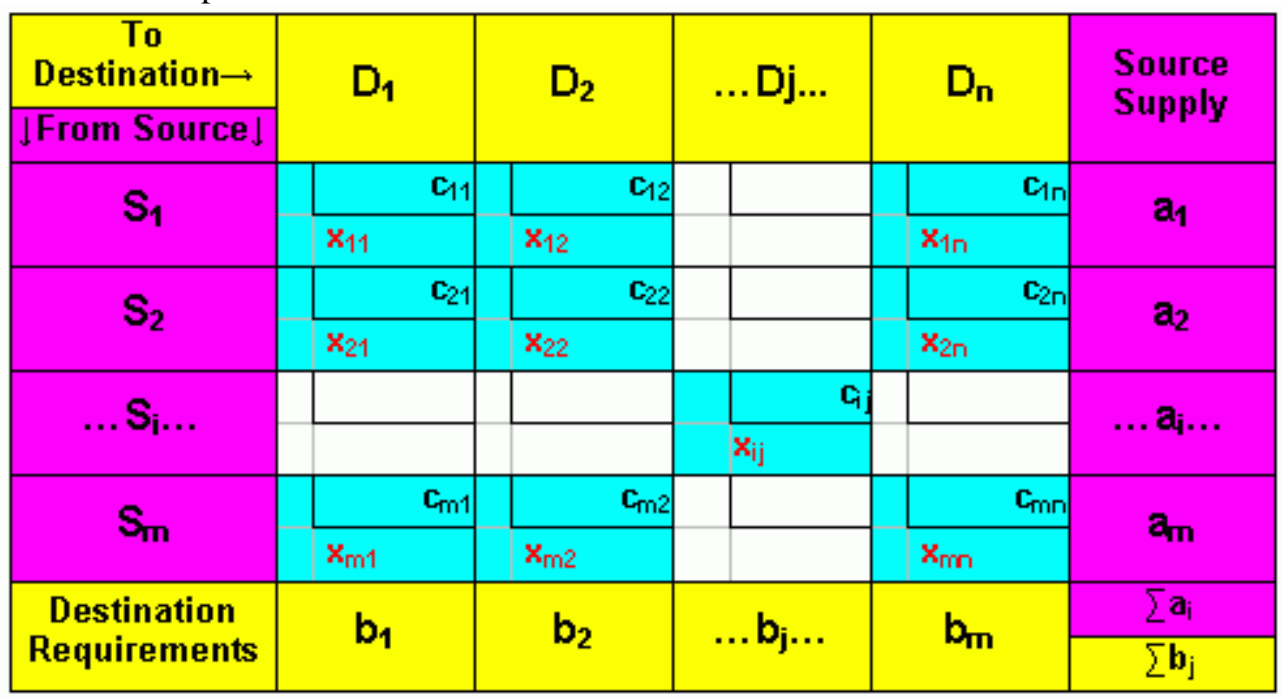

\section{Proposed System:-}

We discuss a new alternative method which gives Initial feasible solution as well as optimal or nearly optimal solution. Apart from the three methods already popular to literature, other two methods called MODI method and Stepping Stone method give the optimal solution. But to get the optimal solution, first we find initial solution from either of three methods discussed. However, the methods discussed in this chapter gives initial as well as either optimal solution or near to optimal solution. Simply put, we can say that if we apply the alternate method, it gives either initial feasible solution as well as optimal solution or near to optimal solution.

Consider the following Transportation Problem:-

Table 3:- Sample cost matrix

\begin{tabular}{|c|c|c|c|c|c|}
\hline & D & E & F & G & Supply \\
\hline A & 19 & 30 & 50 & 10 & 7 \\
\hline B & 70 & 30 & 40 & 60 & 9 \\
\hline C & 40 & 8 & 70 & 20 & 18 \\
\hline Demand & 5 & 8 & 7 & 14 & \\
\hline
\end{tabular}

Step 1: Select the first column (destination) and verify the row (source) which has minimum unit cost. Write that destination under column 1 and corresponding source under column 2. Continue this process for each destination. However, if any destination has more than one same minimum value in different sources then write all these sources under column 2. 
Table 4:- Modified matrix

\begin{tabular}{|c|c|}
\hline Column 1 & Column 2 \\
\hline $\mathrm{D}$ & $\mathrm{A}$ \\
\hline $\mathrm{E}$ & $\mathrm{C}$ \\
\hline $\mathrm{F}$ & $\mathrm{B}$ \\
\hline $\mathrm{G}$ & $\mathrm{A}$ \\
\hline
\end{tabular}

Step 2: Select those destinations under column-1 which have unique source

Step 3: If source under column-2 is not unique then find the difference between minimum and next minimum unit cost for all those destinations where sources are not identical. Since sources are not unique, we find difference between minimum and next minimum for destination

(column 1) E \& F

for $\mathrm{E}: 30-8=22$

for $F$ : $50-40=10$

Step 4: Check the destination which has maximum difference. Select that destination and allocate a minimum of supply and demand to the corresponding cell with minimum unit cost. Delete that row/column where supply/demand is exhausted.

Max difference is 22. So, we allocate to (E, C)

Table 5:- Allocation Table

\begin{tabular}{|c|c|c|c|c|c|}
\hline & D & E & F & G & Supply \\
\hline A & & - & & & 7 \\
\hline B & & - & & & 9 \\
\hline C & & $\mathbf{8}$ & & & 18 \\
\hline Demand & $\mathbf{5}$ & $\mathbf{8}$ & $\mathbf{7}$ & $\mathbf{1 4}$ & \\
\hline
\end{tabular}

We now remove column $\mathrm{E}$

Step 5: Repeat step 1 to step 4 until all the demand and supply are exhausted.

Table 6:- Cost Table

\begin{tabular}{|c|c|c|c|c|}
\hline & D & F & G & Supply \\
\hline A & 19 & 50 & 10 & 7 \\
\hline B & 70 & 40 & 60 & 9 \\
\hline C & 40 & 70 & 20 & 18 \\
\hline Demand & 5 & 7 & 14 & \\
\hline
\end{tabular}

Proceed in same fashion

Table 7:- Modified Table

\begin{tabular}{|c|c|}
\hline Column 1 & Column 2 \\
\hline $\mathrm{D}$ & $\mathrm{A}$ \\
\hline $\mathrm{F}$ & $\mathrm{B}$ \\
\hline $\mathrm{G}$ & $\mathrm{A}$ \\
\hline
\end{tabular}

$\mathrm{B}$ is unique. We allocate to $(\mathrm{F}, \mathrm{B})$

Table 8:- Allocation Table

\begin{tabular}{|c|c|c|c|c|c|}
\hline & D & E & F & G & Supply \\
\hline A & & - & - & & 7 \\
\hline B & & - & $\mathbf{7}$ & & 9 \\
\hline C & & $\mathbf{8}$ & - & & 18 \\
\hline Demand & $\mathbf{5}$ & $\mathbf{8}$ & $\mathbf{7}$ & $\mathbf{1 4}$ & \\
\hline
\end{tabular}

We now remove column $\mathrm{F}$ 
Table 9:- Cost Table

\begin{tabular}{|c|c|c|c|}
\hline & D & G & Supply \\
\hline A & 19 & 10 & 7 \\
\hline B & 70 & 60 & 9 \\
\hline C & 40 & 20 & 18 \\
\hline Demand & 5 & 14 & \\
\hline
\end{tabular}

Proceed in same fashion:

Table 10:- Modified Table

\begin{tabular}{|c|c|}
\hline Column 1 & Column 2 \\
\hline $\mathrm{D}$ & $\mathrm{A}$ \\
\hline $\mathrm{G}$ & $\mathrm{A}$ \\
\hline
\end{tabular}

Sources are not unique; we find difference between minimum and next minimum for destination (column 1$) \mathrm{D} \& \mathrm{G}$ for D: $40-19=21$; for G: $20-10=10$

Max difference is 21 . So, we allocate to $(\mathrm{D}, \mathrm{A})$

Table 11:- Allocation Table

\begin{tabular}{|c|c|c|c|c|c|}
\hline & D & E & F & G & Supply \\
\hline A & 5 & - & - & & 7 \\
\hline B & - & - & 7 & & 9 \\
\hline C & - & 8 & - & & 18 \\
\hline Demand & 5 & 8 & 7 & 14 & \\
\hline
\end{tabular}

Remaining allocation is done directly

Table 12:- Final Allocation Table

\begin{tabular}{|c|c|c|c|c|c|}
\hline & D & E & F & G & Supply \\
\hline A & 5 & - & - & 2 & 7 \\
\hline B & - & - & 7 & 2 & 9 \\
\hline C & - & 8 & - & 10 & 18 \\
\hline Demand & 5 & 8 & 7 & 14 & \\
\hline
\end{tabular}

IBFS: $(5 * 19)+(2 * 10)+(7 * 40)+(2 * 60)+(8 * 8)+(10 * 20)=779$

\section{Snapshots:}

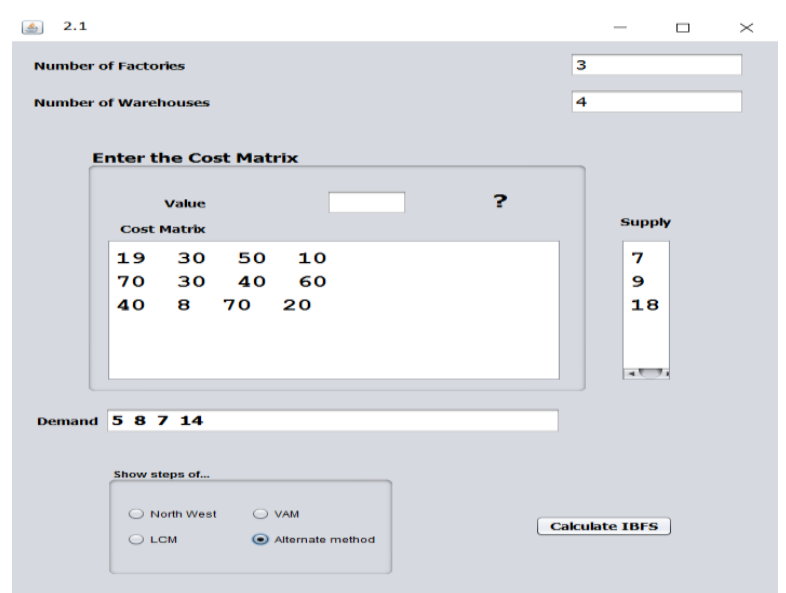

Fig 1:- User input screen for inserting cost matrix, supply and demand 


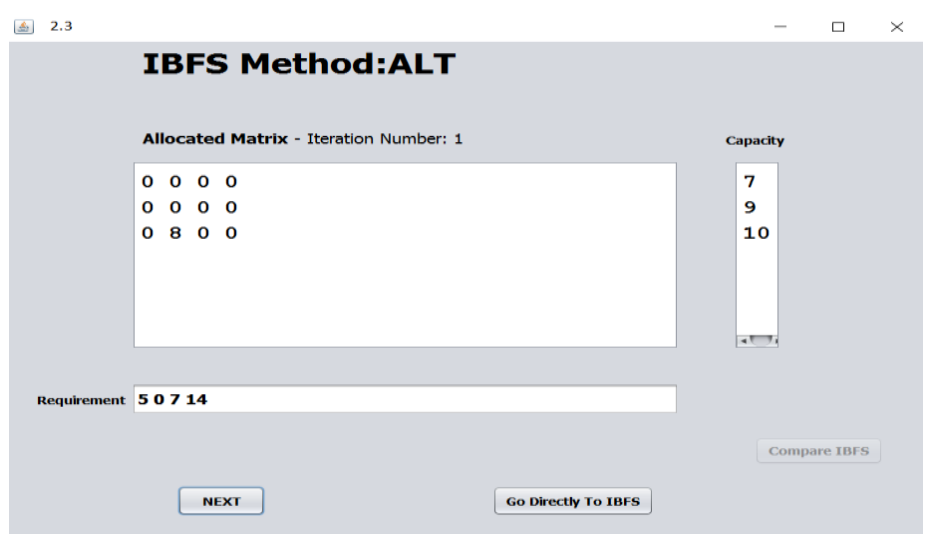

Fig 2:- First iteration for allocating matrices using alternate method

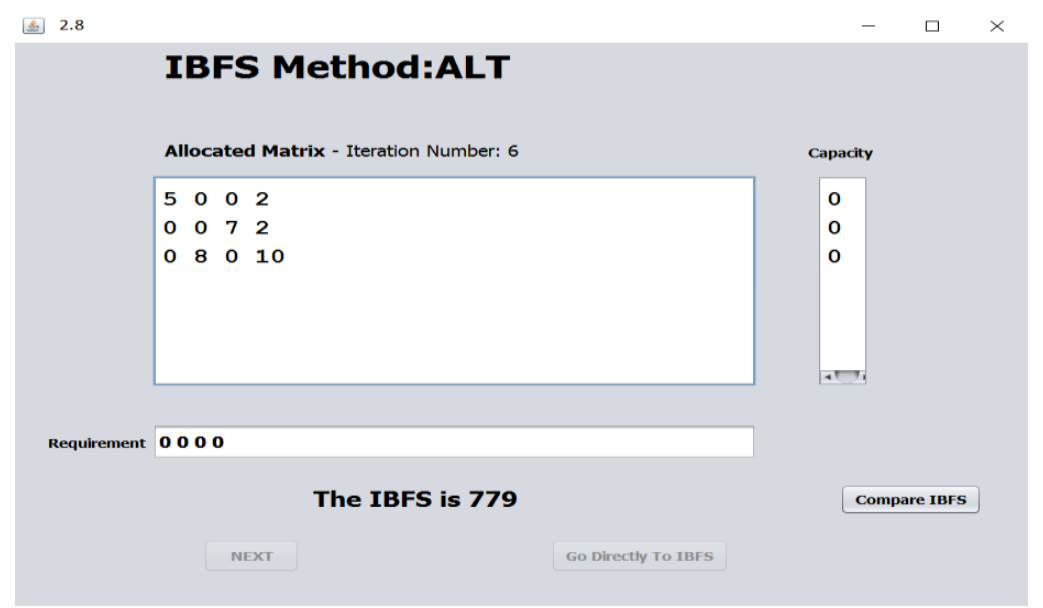

Fig 3:- Last iteration for allocating matrices using alternate method

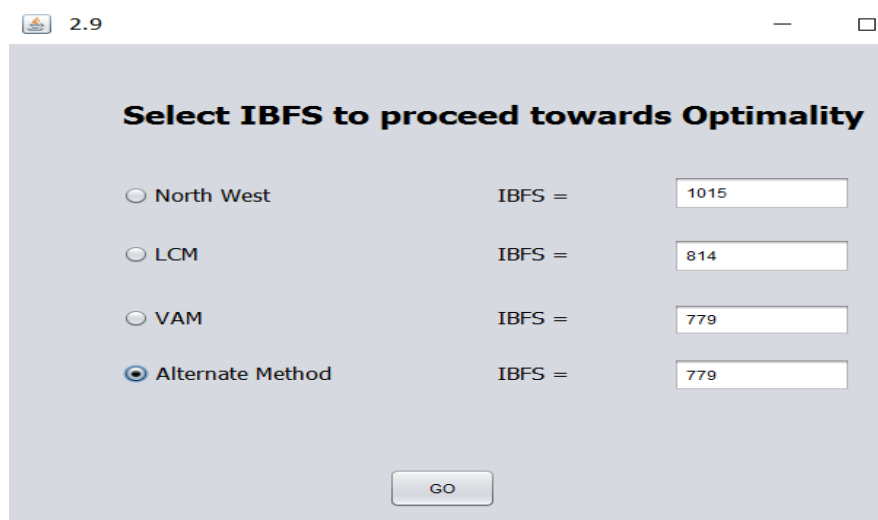

Fig 4:- IBFS of the four methods and option of choosing any one of the method to proceed to optimality 


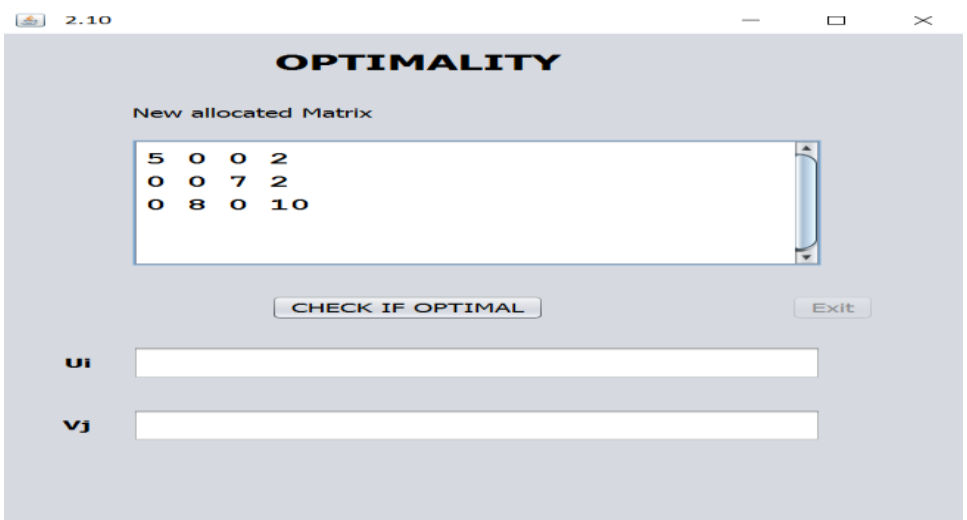

Fig 5:- Checking for optimality

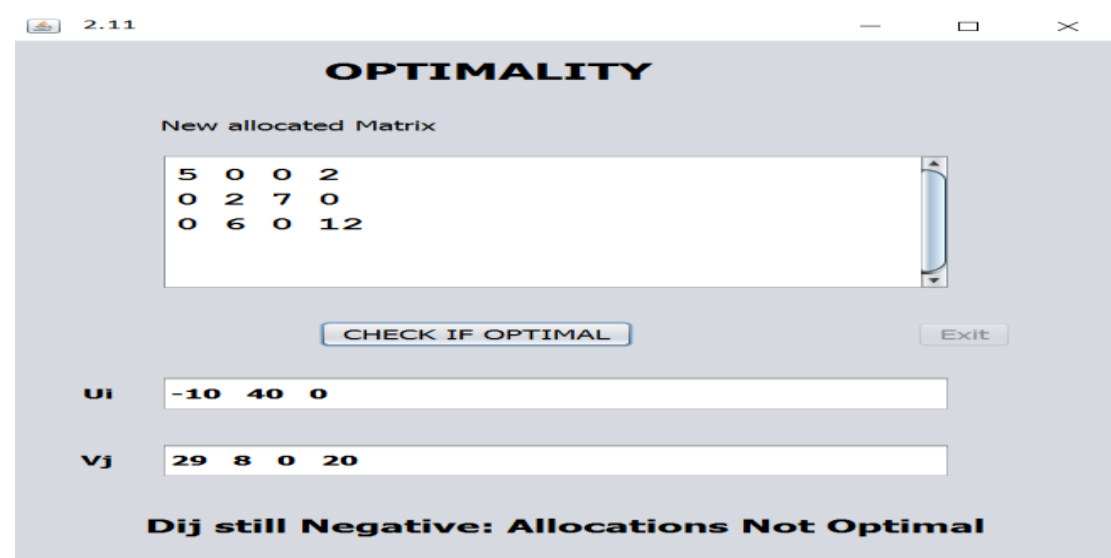

Fig 6:- Dij should be positive for the allocations to be optimal

$\Leftrightarrow 2.12$

\section{OPTIMALITY}

New allocated Matrix
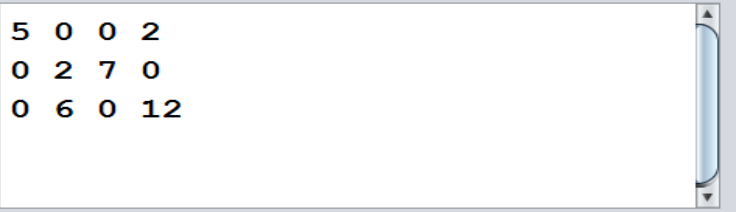

Ui

vj

\section{Optimal Solution: Cost $=\mathbf{7 4 3}$}

Fig 7:- Optimality is reached and value is displayed 


\section{Conclusion:-}

The Transportation Problem, has been, is and will continue to be a topic for further study and advancement. The advantages that lie in finding and perfecting new methods to obtain the feasible solution effectively are manifold. In this paper, an easy algorithm for solving transportation problem has been developed. This work has been a humble attempt at doing just that and implementing the same with a simple user interface. However, merely implementing a new method does not suffice. To be of wider academic study, it is required to substantiate any new proposal with sufficient test cases and conditions.

\section{References:-}

1. Ilija NIKOLIĆ, "TOTAL TIME MINIMIZING TRANSPORTATION PROBLEM" Yugoslav Journal of Operations Research 17 (2007), Number 1, 125-133

2. Abdallah A. Hlayel, Mohammad A. Alia, "SOLVING TRANSPORTATION PROBLEMS USING THE BEST CANDIDATES METHOD"

3. Ramakrishna, C. S. - An Improvement to Goyal's Modified VAM for the Unbalanced Transportaion Problem, J Opl. Res. Soc. Vol. 39, 609-610 (1988).

4. Sultan, A. - Heuristic for Finding an Initial B. F. S. in Transportation Problems, Opsearch Vol. 25, 197-199 (1988).

5. Pandian, P. and Natarajan, G. - A New Method for Finding an Optimal Solution for Transportation Problems, International J. of Math. Sci. \& Engg. Appls. Vol. 4 59-65 (2010).

6. Sudhakar, V. J., Arunsankar, N. and Karpagam, T. - A New approach for finding an Optimal Solution for Transportation Problems, European Journal of Scientific Research, vol. 68, 254-257 (2012).

7. Frederick S. Hillier and Gerald J. Lieberman: Introduction to Operations Research: Concepts and Cases, 8th Edition, Tata McGraw Hill, 2005. 